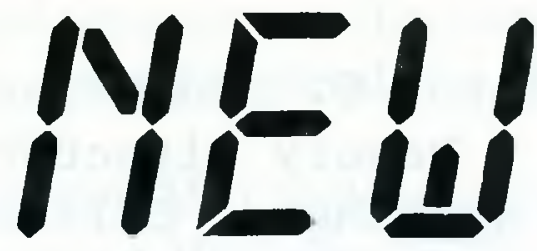

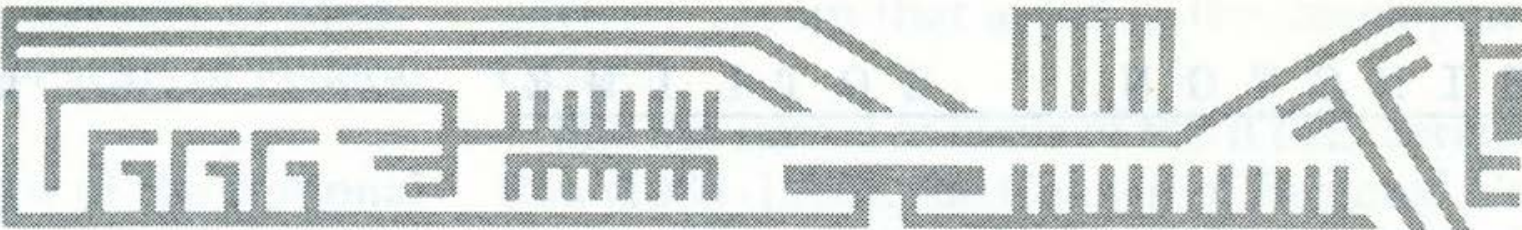 TEEHNOLGGU

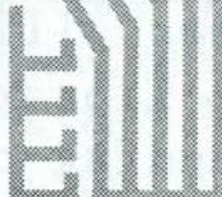

- The Area Business Databank, Inc., a new business reference service that pinpoints information on closely held or private companies and their officers, began monthly service in July. The service scans over 80 local, state and regional business publications throughout the U.S. and Canada. Subscribers receive the complete articles on microfiche accompanied by a fully cross-referenced printed index. ABD also concentrates on regional business statistics, local business trends, new technology, successful entrepreneurs, state tax policies, legislation and regulatory actions, market strategy, site selection, and emerging stocks. For further information, contact Area Business Databank, P.O. Box 829, Louisville, KY 40201; (502) 589-9666.

- Baker \& TAYlor's new BaTaPHONE electronic ordering system, which was previewed at ALA Annual Conference in Los Angeles, became operational on September 1. The system utilizes a hand-held data terminal that is used for ordering titles by keying in the ISBN and the quantity desired. The order information is then transmitted to Baker \& Taylor via toll-free telephone lines. A printed acknowledgment is automatically sent to the library and pre-printed multiple-copy order slips can also be provided. The system can be rented for $\$ 325$ annually. For further information, contact Baker \& Taylor Company, 6 Kirby Avenue, Somerville, NJ 08876; (201) 526-8000.

- NEW YORK UNIVERSITY's Bobst Library held a special ceremony on September 15 to introduce its online public catalog, BOBCAT. The system lists recent holdings of the Bobst Library, the Graduate School of Business Administration, and the Institute of Fine Arts. It also contains information on materials in the member libraries of the Research Library Association of South Manhattan. A total of 100 terminals will soon be installed throughout the system. A Geac 8000 minicomputer serves the BOBCAT system. Additional functions to be added later are a linked authority file, a high-speed printing facility, and a Boolean search system. The system was funded in part by grants from the Carnegie Corporation and the Mellon Foundation.

-Standard Duplicating Machines CorporaTION has acquired the distribution rights for the $\mathrm{T}$ Track System, an anti-theft device that protects general or technical office equipment. The system consists of matching steel post and maze plates that are securely bound to the base of the protected equipment and to the adjacent work surface. Once installed, the system is hidden from view and inaccessible. Installation requires no drilling or mechanical attachment. The equipment ranges in size to accomodate different types of equipment and in price from $\$ 28.50$ to $\$ 92$. For further information, contact Francis Kelly, Standard Duplicating Machines Corp., 10 Connector Road, Andover, MA 01810; (617) 470-1920.

- The University of Texas Health Science Center Library, San Antonio, has selected the Library Information System (LIS) developed by the John Vinton Dahlgren Memorial Library, Georgetown University Medical Center, as its circulation and technical services system. LIS features a miniMEDLINE system that provides quick access to biomedical journal citations and provides an interface with the PHILSOM Serial Management System developed by the Washington University School of Medicine Library. The system became operational this August in the Center's new library building, which contains 34 VT 100 series terminals.

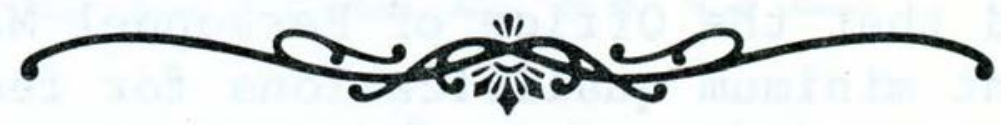

\section{Immroth Award}

ALA's Intellectual Freedom Round Table (IFRT) has called for nominations for the 1984 John Phillip Immroth Memorial Award. The award, established in 1976 in memory of IFRT's founder, honors an individual who has made a notable contribution to intellectual freedom and who has demonstrated remarkable personal courage in the support of intellectual freedom and First Amendment rights.

Past recipients have included Nat Hentoff, Village Voice columnist (1983), Stephen Pico, plaintiff in the Island Trees case, Levittown, New York (1982), and I.F. Stone (1976). The award, a citation and $\$ 500$, will be presented at ALA Annual Conference. Nominations should be submitted by December 1, 1983, to David Cohen, Chair, John Phillip Immroth Memorial Award Committee, 68-71 Bell Boulevard, Bayside, NY 11364. 


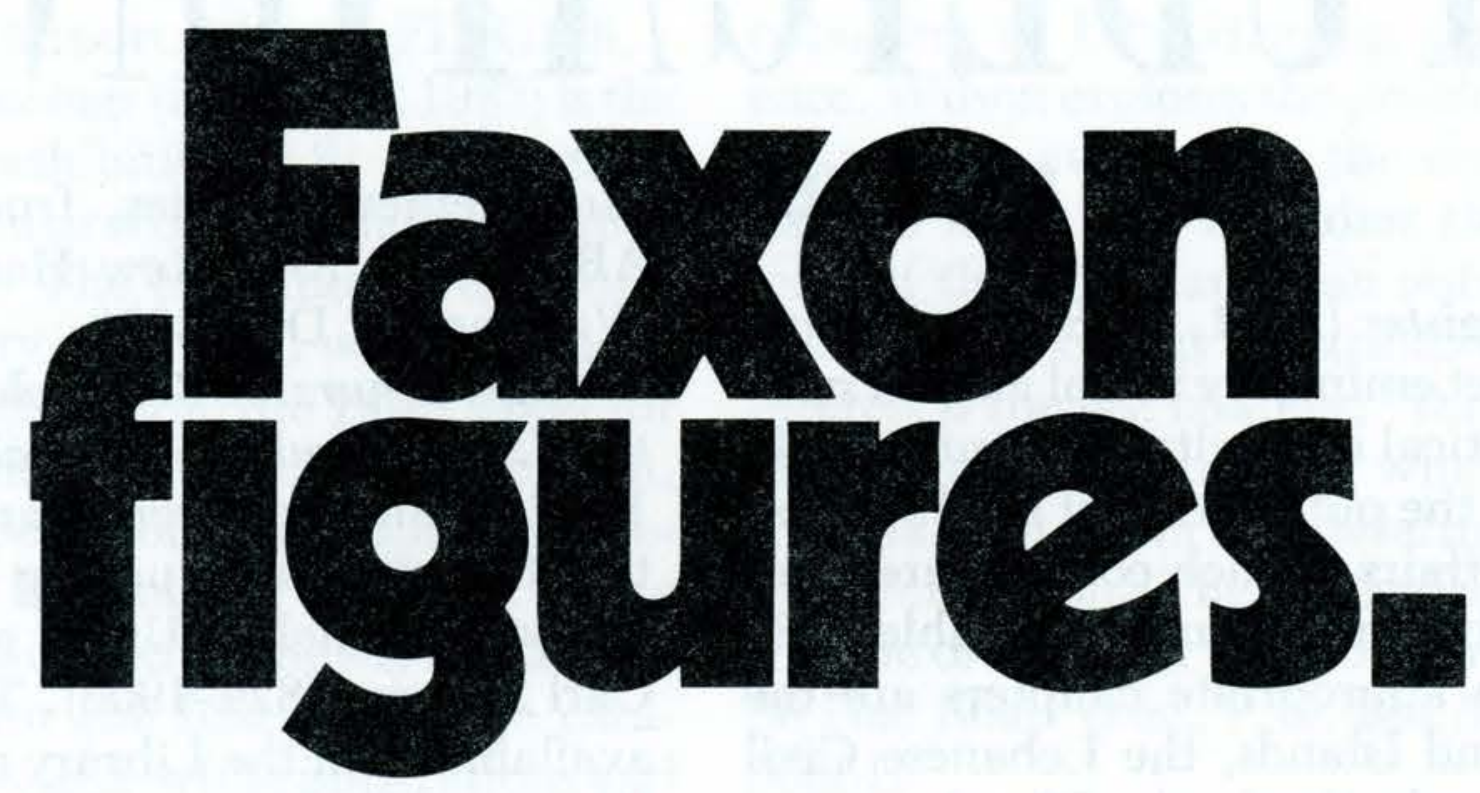

Productivity is a critical concern in today's library. That's why more and more decision makers are looking into Faxon. We can be the best source for all of your journal and continuation subscriptions. Our services enable you to devote your valuable personnel resources to other crucial library functions.

As a full service agent with access to more than 150,000 different periodicals, we can handle ordering, claiming, check-in, and routing. Our growing international network links you to other libraries, publishers, and in the near future, other online systems.

If you can profit from improved productivity, a call to Faxon figures.

1-800-225-6055

or 1-617-329-3350 (collect)

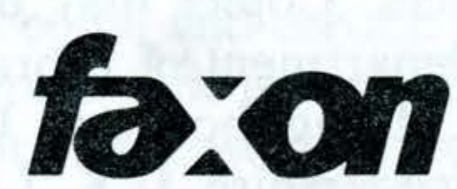

ON THE FRONTIER OF INFORMATION MANAGEMENT

F.W. Faxon Company, Inc. 15 Southwest Park Westwood, MA 02090 